\title{
Pemanfaatan Media Sosial dalam Proses Pembelajaran di SMPN 1 Mojo Kediri
}

\author{
Dina Dahniary Sholekah ${ }^{1}$, Siti Wahyuni ${ }^{2}$ \\ ${ }^{1}$ Institut Agama Islam Tribakti Kediri, ${ }^{2}$ Institut Agama Islam Tribakti Kediri \\ 1yunilirboyo@gmail.com
}

\begin{abstract}
This article examines social media in learning process at SMPN 1 Mojo Kediri. This study found that the use of social media in the learning process was under the supervision and direction of the teacher. If it is outside school hours, students experience difficulties or students encounter difficulties so they can directly communicate through social media to ask questions or discuss with friends or with their teacher. The use of social media also gives a positive influence on student learning achievement. The indication is seen from the condition of students who become more enthusiastic in learning. In this way, the teacher is educating students to use social media wisely. This is one form of social media literacy socialization conducted by teachers for students.
\end{abstract}

Keywords: Learning Process, Social Media.

\begin{abstract}
Abstrak
Artikel ini mengkaji media sosial dalam proses pembelajaran di SMPN 1 Mojo Kediri. Penelitian ini menemukan bahwa pemanfaatan media sosial pada proses pembelajaran berada dalam pengawasan dan pengarahan dari guru. Apabila sudah di luar jam sekolah, siswa mengalami kesusahan atau siswa menemui kesulitan maka mereka bisa dengan langsung melakukan komunikasi melalui media sosial untuk bertanya atau berdiskusi dengan teman atau dengan gurunya. Pemanfaatan media sosial juga memberikan pengaruh positif pada prestasi belajar siswa. Indikasinya tampak dari kondisi siswa yang menjadi lebih bersemangat dalam belajar. Dengan cara itu, guru tengah melakukan edukasi kepada siswa untuk menggunakan sosial media secara bijak. Inilah salah satu bentuk sosialisasi literasi media sosial yang dilakukan guru untuk siswa.
\end{abstract}

Kata Kunci: Proses Pembelajaran, Media Sosial.

\section{Pendahuluan}

Peminat gadget menyentuh semua kalangan masyarakat. ${ }^{1}$ Di dalamnya memuat beragam fitur dan aplikasi seperti aplikasi edukatif, permainan, media sosial, dan beragam jenis aplikasi lainnya. Semua itu dapat diakses dengan koneksi jaringan

\footnotetext{
${ }^{1}$ Zaenal Arifin, "Perilaku Remaja Pengguna Gadget; Analisis Teori Sosiologi Pendidikan," Jurnal Pemikiran Keislaman 26, no. 2 (2015): 287-316, https://doi.org/10.33367/tribakti.v26i2.219.
} 
internet baik melalui ponsel pintar atau laptop. Dengan keberadaannya hampir seluruh masyarakat kota maupun desa selalu menghadirkan media sosial dalam kehidupannya. ${ }^{2}$ Sebagai salah satu fitur dan karakter gadget, media sosial dapat memberikan informasi penggunaan apa saja atau banyak hal, seperti: mengubah pola hidup, mendatangkan kebiasaan-kebiasaan baru bahkan dikatakan kebutuhan yang mampu mengubah perilaku dan cara mereka berkomunikasi. ${ }^{3}$

Hasil survey Asosiasi Penyelenggara Jasa Internet Indonesia (APJJI) tahun 2018 menunjukkan bahwa pengguna internet bagi yang sedang menempuh jenjang pendidikan SMP mencapai angka 80.4 persen. ${ }^{4}$ Berkenaan dengan itu Nisa Khairuni di menginformasikan bahwa perkembangan sosial media terhadap pendidikan akhlak anak di SMPN 2 Banda Aceh memiliki dampak positif berupa kemampuan beradaptasi, sosialisasi, mengelola jaringan pertemanan, dan memudahkan anak-anak menyelesaikan tugas. Sedangkan dampak negatifnya adalah membuat anak-anak lalai sehingga menjadikan mereka kurang disiplin dan malas, membuat anak-anak mudah menyontek, kurang sopan dan mudah bertengkar. ${ }^{5}$

Oleh karena itu, sudah menjadi kewajiban guru melakukan upaya-upaya edukatif untuk mempersiapkan para siswanya sejak dini untuk menghadapi kehidupan di zaman sekarang atau yang akan datang di mana kemampuan-kemampuan khusus dan kemampuan mengelola atau menyaring informasi menjadi hal sangat dibutuhkan. Salah satu upaya guru ialah dengan cara memanfatkan pendekatan pembelajaran yang lebih modern seperti dengan pemanfaatan media sosial dalam pembelajaran. ${ }^{6}$

Pemanfaatan ini menjadi penting agar siswa dapat memahami dan menggunakan media sosial secara bijak sehingga tidak mudah terprovokasi atau tertipu dengan segala hal yang begitu mudah diposting dan disebarluaskan dalam sosial media. Media sosial adalah sarana bersosialisasi secara online di dunia maya dengan para pengguna media sosial bisa dengan mudah berpartisipasi, berkomunikasi, berinteraksi dan saling berbagi informasi dengan cepat dan terbaru. Berkaitan dengan itu, Juliswara menegaskan bahwa

\footnotetext{
${ }^{2}$ Sulidar Fitri, "Dampak Positif dan Negatif Sosial Media terhadap Perubahan Sosial Anak," Naturalistic: Jurnal Kajian Penelitian Pendidikan Dan Pembelajaran 1, no. 2 (April 17, 2017): 118, https://doi.org/10.35568/naturalistic.v1i2.5.

${ }^{3}$ Fitri, $118-19$.

${ }^{4}$ Asosiasi Penyelenggara Jasa Internet Indonesia (APJJI), Penetrasi dan Profil Perilaku Pengguna Internet Indonesia: Survey 2018, diakses dari https://apjii.or.id/content/read/39/410/Hasil-SurveiPenetrasi-dan-Perilaku-Pengguna-Internet-Indonesia-2018

${ }^{5}$ Nisa Khairuni, "Dampak Positif dan Negatif Sosial Media terhadap Pendidikan Akhlak Anak (Studi Kasus di SMP Negeri 2 Kelas VIII Banda Aceh)," JURNAL EDUKASI: Jurnal Bimbingan Konseling 2, no. 1 (August 30, 2016): 91-106, https://doi.org/10.22373/je.v2i1.693.

${ }^{6}$ Udin Saefudin Sa'ud, Inovasi Pendidikan (Jakarta: Alfabeta, 2008), 200.
} 
keberadaan internet sebagai media online dapat menyebarluaskan informasi yang belum pasti kebenarannya secara cepat. ${ }^{7}$

Kecanggihan dan kecepatan media sosial juga ikut mempengaruhi berlangsungnya dunia pendidikan sehingga dapat membawa perubahan baik secara administrasi, promosi, sosialisasi dan sebagainya. Kenyataan ini merupakan bentuk respon positif yang dapat dikembangkan dalam melakukan inovasi dalam pendidikan dan pembelajaran. Para siswa diperkenalkan atau dianjurkan untuk ikut serta dalam berinteraksi melalui media sosial sehingga dapat memberikan stimulus pengembangan diri, problem solving, kreativitas dan inovasi. ${ }^{8}$

Apabila dikaitkan dengan proses pembelajaran, maka media sosial merupakan bagian dari media pembelajaran yang tengah mengalami pemutakhiran sesuai dengan kondisi zaman. Sebagai bagian dari media pembelajaran berarti pemanfaatan media sosial juga semestinya mampu mengarahkan proses pembelajaran berlangsung lebih efektif dan efisien. Tetapi apabila media sosial tidak digunakan sebagaimana mestinya atau hanya digunakan untuk mengikuti zaman atau digunakan untuk hal yang tidak baik maka tentunya pemanfaatan media sosial dalam kegiatan belajar mengajar akan berdampak negatif, seperti kecanduan dan lebih asik berada di dunia maya, lalai belajar, dan lain sebagainya. ${ }^{9}$ Kenyataan ini juga menjadi pendorong bagi guru untuk terus melakukan inovasi dengan memanfaatkan kemajuan teknologi informasi dan komunikasi agar pengemasan pembelajaran yang dirancang guru mampu menarik perhatian dan minat siswa untuk belajar.

Lembaga pendidikan saat ini telah memperkenalkan dan memulai penggunaan teknologi informasi dan komunikasi sebagai basis pembelajaran yang lebih mutakhir. ${ }^{10}$ Ditambah mayoritas sekolah saat ini telah menggunakan internat, Kurikulum 2013, pelaksanaan Ujian Nasional (UN) berbasis komputer, termasuk. SMPN 1 Mojo Kediri. Bagi peneliti SMPN 1 Mojo Kediri adalah suatu lembaga pendidikan yang layak dan penting untuk diteliti karena beberapa hal, yaitu: fasilitas yang lengkap sehingga dapat dimanfaatkan dalam kegiatan belajar mengajar dan dapat meningkatkan kualitas siswa,

\footnotetext{
${ }^{7}$ Vibriza Juliswara, "Mengembangkan Model Literasi Media yang Berkebhinnekaan dalam Menganalisis Informasi Berita Palsu (Hoax) di Media Sosial," Jurnal Pemikiran Sosiologi 4, no. 2 (November 6, 2017): 143, https://doi.org/10.22146/jps.v4i2.28586.

${ }^{8}$ Fitri, 119.

${ }^{9}$ Edi Suryadi, Muhammad Hidayat Ginanjar, and Muhamad Priyatna, "Penggunaan Sosial Media Whatsapp Pengaruhnya terhadap Disiplin Belajar Peserta Didik Pada Mata Pelajaran Pendidikan Agama Islam (Studi Kasus Di SMK Analis Kimia YKPI Bogor)," Edukasi Islami: Jurnal Pendidikan Islam 7, no. 01 (April 16, 2018): 3, https://doi.org/10.30868/ei.v7i01.211.

${ }^{10}$ Fitri, 119.
} 
selalu mengikuti perkembangan zaman, dapat memberikan inovasi, lengkap dengan keberagaman input siswanya, mulai dari golongan santri, menengah ke atas, menengah ke bawah dan ada pula yang beragama Islam serta Kristen, serta letaknya yang strategis berada di pusatnya desa Mojo. Dengan demikian, tulisan ini bermaksud untuk menguraikan pemanfaatan media sosial dalam proses pembelajaran beserta dampaknya yang berlangsung di SMPN 1 Mojo Kediri.

\section{Metode Penelitian}

Penelitian ini merupakan penelitian lapangan (field research) dengan metode penelitian kualitatif. Penelitian ini berlangsung di SMPN 1 Mojo Kediri. Teknik pengumpulan data dilakukan dengan melakukan wawancara, observasi, dan dokumentasi. Data yang telah terkumpul kemudian dianalisis secara induktif dengan terjun ke lapangan, mempelajari, menganalisis, menafsirkan dan menarik kesimpulan dari fenomena yang ada di lapangan. ${ }^{11}$ Proses analisis data mencakup beberapa tahap, antara lain reduksi data, penyajian data, dan penarikan kesimpulan. Sedangkan pengecekan keabsahan data dilakukan dengan melakukan perpanjangan pengamatan, triangulasi, dan pengecekan teman sejawat. ${ }^{12}$

\section{'Literasi' Media Sosial}

Media sosial tengah menyentuh banyak lapisan sosial, termasuk anak-anak. Ini sejalan dengan penetrasi pengguna internet yang setiap tahun semakin meningkat. Hasil survey Asosiasi Penyelenggara Jasa Internet Indonesia (APJJI) menunjukkan bahwa pada tahun 2017 pengguna internet secara nasional mencapai angka 143,26 juta jiwa dari total populasi penduduk Indonesia yang berjumlah 262 juta jiwa atau sebanyak 54,68 persen. Jumlah ini semakin meningkat pada tahun 2018, yaitu mencapai 171,17 juta jiwa dari total populasi 264,16 juta jiwa atau mencapai angka 64,8 persen. Dari keseluruhan jumlah itu, kontribusi terbesar berada di pulau Jawa, yaitu sebanyak 55,7 persen. Pada tingkat provinsi, Jawa Timur menduduki peringkat ketiga $(13,5 \%)$ setelah Jawa Tengah $(14,3)$ dan Jawa Barat $(16,7 \%)$. Dilihat dari tingkat pendidikan secara

\footnotetext{
${ }^{11}$ Margono, Metodologi Penelitian Pendidikan (Jakarta: PT. Rineka Cipta, 2004), 38.

${ }^{12}$ Nusa Putra dan Santi Lisnawati, Penelitian Kualitatif Pendidikan Agama Islam (Bandung: PT. Remaja Rosdakarya, 2013), 44-46.
} 
nasional, pengguna internet bagi yang sedang menempuh jenjang pendidikan SMP mencapai angka 80.4 persen. $^{13}$

Kenyataan ini tidak dapat dipungkiri. Namun harus dikelola dengan baik agar penggunaannya tidak mengarah hanya pada hal yang bersifat semata-mata hiburan bahkan berdampak negatif. Berkenaan dengan itu maka muncul pendapat banyak ahli yang mendefinisikan media sosial. Ridwan Sanjaya dalam Nugraha mendefinisikannya sebagai suatu media berbasis jaringan internet yang memungkinkan para penggunanya melakukan komunikasi secara langsung melalui dunia maya dengan berbagai fasilitas yang ada di dalamnya seperti chatting, video call, dan sebagainya. Melalui fasilitas itu, para pengguna sosial media dapat berbagi informasi secara luar atau terbatas sesuai kehendaknya dan seterusnya. ${ }^{14}$

Ardianto Elvinaro juga mengemukakan bahwa pada dasarnya media sosial sama dengan media massa. Media massa ini dibagi menjadi dua bagian yaitu media cetak, seperti: surat kabar, majalah dan media elektronik seperti: radio, tv, media online (internet). ${ }^{15}$ Media sosial juga berkaitan dengan proses demokratisasi. Berkenaan dengan itu, Ismail mengemukakan bahwa media sosial adalah manifestasi demokratisasi media informasi yang terbuka secara global melalui jaringan internet. ${ }^{16}$ Beberapa media sosial yang sangat popular di zaman sekarang seperti whatsapp, facebook, instagram, twitter dan lain sebagainya. Di dalamnya memuat fasilitas chatting, yaitu fasilitas yang dapat digunakan untuk berkomunikasi dalam bentuk pengiriman pesan. ${ }^{17}$ Fasilitas ini banyak dimanfaatkan pengguna karena pengiriman pesannya jauh lebih canggih (dapat melampirkan gambar, foto, video, dan update status/histori) dan murah dibandingkan fasilitas pengiriman pesan melalui aplikasi konvensional Short Message Sevice (SMS).

Adapun konsep literasi sosial media mengacu pada pendapat Azimah Soebagijo dalam Nugraha yang mendefinisikannya sebagai kemampuan seseorang atau pengguna dalam mengakses, menafsirkan, menganalisis, mengevaluasi dan menggunakan seluruh

\footnotetext{
${ }^{13}$ Asosiasi Penyelenggara Jasa Internet Indonesia (APJJI), Penetrasi dan Profil Perilaku Pengguna Internet Indonesia: Survey 2018, diakses dari https://apjii.or.id/content/read/39/410/Hasil-SurveiPenetrasi-dan-Perilaku-Pengguna-Internet-Indonesia-2018

${ }^{14}$ Iswandi Syahputra, "Media Sosial dan Prospek Muslim Kosmopolitan: Konstruksi \& Peran Masyarakat Siber pada Aksi Bela Islam,” Jurnal Komunikasi Islam 8, no. 1 (October 1, 2018): 21, https://doi.org/10.15642/jki.2018.1.1.19-40.

${ }^{15}$ Elvinaro Ardianto, Komunikasi Masa Suatu Pengantar (Bandung: Simbiosa Rekatama Media, 2007), 103.

${ }^{16}$ Ismail Ismail, "Peran Guru Pendidikan Agama Islam Dalam Mengantisipasi Dampak Penggunaan Media Sosial Bagi Siswa Sekolah Menengah Pertama," IQRO: Journal of Islamic Education 1, no. 2 (December 17, 2018): 109, https://doi.org/10.24256/iqro.v1i2.493.

${ }^{17}$ Agus Santoso, "Media Literacy Siswa Muslim Surabaya dalam Penggunaan Internet," Jurnal Komunikasi Islam 5, no. 1 (June 4, 2015): 83-97, https://doi.org/10.15642/jki.2015.5.1.83-97.
} 
bentuk dan konten media. ${ }^{18}$ Dengan kata lain, literasi di sini berkaitan dengan kemampuan berpikir kritis seseorang agar dapat memperoleh makna sebenarnya dalam konten media dan mengelola informasi secara bijak.

Berkenaan dengan konsep demokratisasi media sosial sebagai bagian dari proses demokratisasi, maka literasi media sosial menjadi penting untuk disosialisasikan pada seluruh lapisan masyarakat agar mereka tidak mudah percaya begitu saja pada informasi yang ada atau dibagikan melalui media sosial tanpa melakukan kroscek atas informasi tersebut. Ini berarti literasi media sosial menjadi salah satu konsep penting untuk menanggulangi berita bohong (hoax) yang mudah dan cepat beredar menuju masyarakat cerdas. Masyarakat cerdas dalam konteks ini adalah masyarakat yang dalam dirinya mampu memilih dan memilah konten media dengan bijak karena sebagai konsumen media masyarakat juga mampu melakukan partisipasi aktif dalam menumbuhkan sikap kritis atas segala sajian media. ${ }^{19}$

Untuk itu, sekolah menjadi salah satu sarana efektif dalam mengedukasi anakanak agar cerdas bermedia sosial. Dalam hal ini Arnus menjelaskan bahwa salah satu sasaran literasi media adalah anak-anak mulai rentang usia 0-13 tahun karena dalam usia itu anak-anak masih kurang pengetahuan tentang konstruksi media. ${ }^{20}$ Proses implementasinya dapat dilakukan secara formal yang berangkat dari kebijakan sekolah yang terstuktur secara rapi dan terarah maupun secara kultural yang dilakukan oleh guru meski belum ada kebijakan dari sekolah mengenai hal itu. Apalagi jika mempertimbang hasil survey nasional yang menemukan bahwa 80.4 persen siswa tingkat sekolah menengah pertama adalah pengguna internet.

\section{Hasil Penelitian}

Pemanfaatan media sosial dalam proses pembelajaran memiliki manfaat tersendiri. Di SMPN Mojo Kediri, guru mengambil peran untuk memulai pemanfaatan media sosial. Indikasinya tampak guru yang menganjurkan siswa untuk membuat grup WhatsApp. Salah seorang siswi menyatakan merasa lebih senang dan bersemangat jika belajar dengan menggunakan media sosial karena memperluas pengetahuan dan dapat merujuk berbagai sumber dan merasa lebih mudah mengingat informasi. Dia juga

\footnotetext{
${ }^{18}$ Muhamad Tisna Nugraha, "Budaya Literasi dan Pemanfaatan Sosial Media pada Masyarakat Akademik," At-Turats 11, no. 2 (January 25, 2018): 124, https://doi.org/10.24260/at-turats.v11i2.884.

${ }^{19}$ Advan Navis Zubaidi, "Urgensi Literasi Media di Tengah Sinisme Antarsuku, Agama, Ras, dan Golongan," Jurnal Komunikasi Islam 8, no. 1 (October 1, 2018): 114, https://doi.org/10.15642/jki.2018.1.1.111-128.

${ }^{20}$ Sri Hadijah Arnus, "Literasi Media: Cerdas dan Bijak Menikmati Konten Media Baru," Al-Munzir 10, no. 1 (March 25, 2018): 131-50, https://doi.org/10.31332/am.v10i1.802.
} 
mengungkapkan bahwa lebih senang mengerjakan tugas dengan menggunakan media sosial, lebih senang berdiskusi melalui media sosial, lebih aktif menyampaikan pendapatnya melalui dunia maya dari pada menyampaikan pendapatnya di dunia nyata (diskusi dalam kelas). ${ }^{21}$

Pernyataan itu sejalan dengan pengamatan peneliti ketika melakukan observasi di kelas VII. Dalam kesempatan itu, seluruh siswa menjawab secara serentak bahwa mereka lebih senang belajar menggunakan media sosial, terutama pada mata pelajaran bahasa Inggris. Alasannya adalah mereka merasa senang karena lebih mudah untuk memahami, lebih mudah untuk menghafal dan lebih mudah dalam mempraktikkan kosa kata bahasa Inggris. ${ }^{22}$

Pada kesempatan lain salah seorang siswi kelas VIII mengungkapkan bahwa dengan pemanfaatan media sosial pada kegiatan belajar mengajar dapat meningkatkan minat, motivasi, semangat pada saat belajar di kelas, sehingga nilai yang didapatnya selalu mengalami peningkatan. Dia juga menyatakan bahwa mata pelajaran yang sering menggunakan media sosial dalam pembelajaran di kelas adalah mata pelajaran: Bahasa Indonesia, Ilmu Pengetahuan Sosial (IPS), Ilmu Pengetahuan Alam (IPA), Bahasa Inggris, Pendidikan Kewarganegaraan, Teknologi Informasi dan Komunikasi, Seni budaya, dan lain sebagainya. Mayoritas mata pelajaran di sekolah ini telah memanfaatkan media sosial sebagai sarana dalam mengakses sumber belajar untuk keperluan kegiatan belajar mengajar. ${ }^{23}$

Penjelasan di atas menunjukkan bahwa beberapa guru di SMPN 1 Mojo Kediri telah memanfaatkan media sosial sebagai salah satu cara mentransfer ilmu, sebagai sumber belajar dan sebagai penunjang dalam kegiatan belajar mengajar. Mayoritas siswa menyatakan lebih senang belajar dengan menggunakan media sosial dari pada belajar dengan cara mencatat di buku atau berdiskusi di dalam kelas. Mereka juga mengungkapkan bahwa dengan bantuan media sosial mereka bisa lebih aktif, dan tidak malu-malu bertanya dengan teman atau dengan gurunya. Mengingat penggunaan media sosial bisa di mana saja dan kapan saja, siswa yang menemukan kesulitan bisa langsung bertanya kepada teman maupun guru. Dengan demikian, terciptalah interaksi edukatif antara siswa dan guru yang dapat menguatkan motivasi siswa sehingga siswa memiliki

\footnotetext{
${ }^{21}$ Weni Marlindasari, Interview, November 30, 2018.

${ }^{22}$ Observasi, November 30, 2018.

${ }^{23}$ Nuriza Salsabila, Interview, September 29, 2018.
} 
rasa semangat belajar lebih giat dan tentu akan memengaruhi hasil atau prestasi belajar mereka.

Kenyataan ini sejalan dengan pendapat Rosenberg tentang perkembangan penggunaan teknologi informasi dan komunikasi dalam proses pembelajaran yang mencakup 5 pergeseran, antara lain: pergeseran dari penelitian menjadi penampilan, pergeseran dari ruang kelas ke di mana dan kapan saja, pergeseran dari kertas ke online, pergeseran fasilitas fisik ke fasilitas jaringan kerja dan pergeseran dari waktu siklus ke waktu nyata. ${ }^{24}$ Beberapa pergeseran yang terjadi harus mendapatkan perhatian dan pengarahan yang bersifat edukatif dari guru agar siswa tidak kebablasan dalam menggunakan media sosial dan memahami berbagai dampaknya.

Di SMPN 1 Mojo Kediri, siswa/siswi tidak diperbolehkan membawa handphone ke sekolah. Namun, guru menganjurkan pada siswa untuk membuat grup WhatsApp. Grup itu tidak hanya beranggotakan para siswa/siswi, melaikan guru juga terdaftar sebagai anggota grup. Dengan begitu, guru dapat memberikan pengawasan, pengarahan, mengingatkan akan tugas atau pekerjaan rumah. Melalui grup itu juga guru dapat terus membangun konektivitas dengan para siswa/siswi sehingga grup itu menjadi lebih bermakna dan bernuansa edukatif. Grup WhatsApp untuk kelas IX H diberi nama Squed H.

Pemanfaatan grup sebagai salah satu media komunikasi edukatif seperti tanya jawab yang berkembang menjadi sebuah diskusi juga sejalan dengan penjelasan seorang siswi pada bagian sebelumnya. Cara pemanfaatan media sosial ini dapat dijadikan modal awal untuk meningkatkan komunikasi edukatif yang efektif antara guru dengan siswa/siswi sekaligus mengedukasi mereka. Apalagi jika guru mata pelajaran lain juga melakukan hal serupa untuk membangun keakraban dengan para siswa/siswi dan mengarahkan mereka pada komunikasi edukatif yang berlangsung di luar jam belajar di sekolah.

Cara ini juga tentu efektif apabila dikembangkan pada pemahaman tentang literasi media sosial. Setidaknya agar siswa/siswi memahami bahwa media sosial dapat digunakan secara positif bahkan untuk kepentingan pembelajaran. Jadi mereka tidak selalu menganggap media sosial sebagai sarana sosialiasasi diri dengan orang lain atau sekadar hiburan karena konsep literasi bukan bermakna sempit yang hanya dimaknai

\footnotetext{
${ }^{24}$ Marc J Rosenberg, Strategies for Delivering Knowledge in the Digital Age (USA: McGraw-Hill Companies, 2001), 1.
} 
'melek' media sosial. Tapi juga mampu memanfaatkan media sosial secara positif karena media sosial juga mempunyai dampak positif dan negatif.

Tanpa perhatian dan pengarahan guru, maka bukan tidak mungkin pemanfaatan itu akan berujung pada berbagai perilaku menyimpang baik secara moral seperti sopan santun maupun penyimpangan intelektual seperti kebiasaan menyontek dan seterusnya. Jika hal ini dibiarkan begitu saja, maka pada tingkat pendidikan yang lebih tinggi mereka akan rentan terjebak dalam plagiarism terutama dalam mengerjakan tugas harian ataupun tugas akhir karena kebiasaan itu telah dipupuk sejak mereka mengenyam pendidikan menengah lewat kebiasaan menyontek.

Belum lagi dampak negatif lain yang mungkin akan menjangkiti mereka karena kurangnya perhatian dan pengarahan dari guru dalam bermedia sosial. Jadi, upaya guru di SMPN 1 Mojo Kediri dapat dikatakan sebagai tindakan preventif agar para siswa dapat memanfaatkan media sosial secara bijak dan menjalin model komunikasi yang lebih kekinian sesuai dengan tuntutan dan perkembangan zaman yang dialami siswa. Cara ini juga memberikan kemudahan pada guru untuk mengetahui karakter dan permasalahan yang tengah dialami siswa. Bahkan guru juga dapat mengetahui tren yang sedang hangat di kalangan para siswa yang dapat dijadikan acuan atau bahan untuk mengemas pembelajaran yang lebih efektif dan efisien.

\section{Penutup}

Pemanfaatan media sosial dalam kegiatan belajar mengajar di SMPN 1 Mojo Kediri berlangsung dalam pengawasan dan pengarahan dari guru. Pemanfaatan media sosial yang dikelola secara positif tentu akan memberikan dampak positif bagi siswa dalam menggunakan media sosial. Artinya siswa menjadi lebih semangat dalam belajar, terciptanya motivasi, lebih banyak sumber belajar atau pengetahuan yang mereka dapatkan sehingga menciptakan prestasi belajar siswa yang selalu naik atau meningkat.

\section{Daftar Rujukan}

Ardianto, Elvinaro. Komunikasi Masa Suatu Pengantar. Bandung: Simbiosa Rekatama Media, 2007..

Arifin, Zaenal. "Perilaku Remaja Pengguna Gadget; Analisis Teori Sosiologi Pendidikan." Jurnal Pemikiran Keislaman 26, no. 2 (2015): 287-316. https://doi.org/10.33367/tribakti.v26i2.219. 
Arnus, Sri Hadijah. "Literasi Media: Cerdas dan Bijak Menikmati Konten Media Baru." Al-Munzir 10, no. 1 (March 25, 2018): 131-50. https://doi.org/10.31332/am.v10i1.802.

Asosiasi Penyelenggara Jasa Internet Indonesia (APJJI), Penetrasi dan Profil Perilaku Pengguna Internet Indonesia: Survey 2018, diakses dari https://apjii.or.id/content/read/39/410/Hasil-Survei-Penetrasi-dan-PerilakuPengguna-Internet-Indonesia-2018

Fitri, Sulidar. "Dampak Positif dan Negatif Sosial Media terhadap Perubahan Sosial Anak." Naturalistic : Jurnal Kajian Penelitian Pendidikan Dan Pembelajaran 1, no. 2 (April 17, 2017): 118-23. https://doi.org/10.35568/naturalistic.vli2.5.

Ismail, Ismail. "Peran Guru Pendidikan Agama Islam Dalam Mengantisipasi Dampak Penggunaan Media Sosial Bagi Siswa Sekolah Menengah Pertama." IQRO: Journal of Islamic Education 1, no. 2 (December 17, 2018): 105-20. https://doi.org/10.24256/iqro.v1i2.493.

Juliswara, Vibriza. "Mengembangkan Model Literasi Media yang Berkebhinnekaan dalam Menganalisis Informasi Berita Palsu (Hoax) di Media Sosial.” Jurnal Pemikiran Sosiologi 4, no. 2 (November 6, 2017): 142-64. https://doi.org/10.22146/jps.v4i2.28586.

Khairuni, Nisa. "Dampak Positif dan Negatif Sosial Media terhadap Pendidikan Akhlak Anak (Studi Kasus di SMP Negeri 2 Kelas VIII Banda Aceh)." JURNAL EDUKASI: Jurnal Bimbingan Konseling 2, no. 1 (August 30, 2016): 91-106. https://doi.org/10.22373/je.v2i1.693.

Margono. Metodologi Penelitian Pendidikan. Jakarta: PT. Rineka Cipta, 2004.

Marlindasari, Weni. Interview, November 30, 2018.

Nugraha, Muhamad Tisna. "Budaya Literasi dan Pemanfaatan Sosial Media pada Masyarakat Akademik." At-Turats 11, no. 2 (January 25, 2018): 124. https://doi.org/10.24260/at-turats.v11i2.884.

Putra, Nusa dan Santi Lisnawati. Penelitian Kualitatif Pendidikan Agama Islam. Bandung: PT. Remaja Rosdakarya, 2013.

Rosenberg, Marc J. Strategies for Delivering Knowledge in the Digital Age. USA: McGraw-Hill Companies, 2001.

Salsabila, Nuriza, Interview, September 29, 2018.

Santoso, Agus. "Media Literacy Siswa Muslim Surabaya dalam Penggunaan Internet." Jurnal Komunikasi Islam 5, no. 1 (June 4, 2015): 83-97. https://doi.org/10.15642/jki.2015.5.1.83-97.

Sa’ud, Udin Saefudin. Inovasi Pendidikan. Jakarta: Alfabeta, 2008.

Suryadi, Edi, Muhammad Hidayat Ginanjar, and Muhamad Priyatna. "Penggunaan Sosial Media Whatsapp Pengaruhnya terhadap Disiplin Belajar Peserta Didik 
pada Mata Pelajaran Pendidikan Agama Islam (Studi Kasus Di SMK Analis Kimia YKPI Bogor).” Edukasi Islami: Jurnal Pendidikan Islam 7, no. 01 (April 16, 2018): 1-22. https://doi.org/10.30868/ei.v7i01.211.

Syahputra, Iswandi. "Media Sosial dan Prospek Muslim Kosmopolitan: Konstruksi \& Peran Masyarakat Siber pada Aksi Bela Islam." Jurnal Komunikasi Islam 8, no. 1 (October 1, 2018): 19-40. https://doi.org/10.15642/jki.2018.1.1.19-40.

Zubaidi, Advan Navis. "Urgensi Literasi Media di Tengah Sinisme Antarsuku, Agama, Ras, dan Golongan." Jurnal Komunikasi Islam 8, no. 1 (October 1, 2018): 11128. https://doi.org/10.15642/jki.2018.1.1.111-128. 